\title{
Uma interpretação discursiva sobre o real da atividade docente no ensino superior: dificuldades e super-ações*
}

\author{
A discursive interpretation about the real activity of \\ teaching in higher education: difficulties and overcomings
}

Siderlene MUNIZ-OLIVEIRA

(UTFPR)

\section{RESUMO}

Este artigo tem por objetivo apresentar os resultados de uma análise de um texto produzido por um professor de ensino superior em que identificamos representações construidas sobre o seu trabalho efetivamente realizado a partir dos niveis enunciativo e semântico (Machado \& Bronckart 2009). Seguimos o interacionismo sociodiscursivo (Bronckart 2006, 2008), que atribui ao agir e à linguagem papel fundamental no desenvolvimento humano, e a Psicologia do Trabalho (Clot 2006, 2010) que estudam situações de trabalho. Para a geração do texto em análise, utilizamos um procedimento denominado instrução ao sósia com um professor experiente da área de estudos da linguagem de uma universidade pública. Como resultado, identificamos elementos que remetem a dificuldades para a realização de algumas atividades de trabalho, mas também a superações, evidenciado o real da atividade de trabalho do professor.

Palavras-chave: ensino superior; real de atividade; trabalho docente; interacionismo sociodiscursivo; Psicologia do Trabalho.

\footnotetext{
* Dados resultantes da tese "O trabalho representado do professor de pós-graduação de uma universidade pública", defendida em 2011 no Programa de Estudos Pós-Graduados em Linguística Aplicada e Estudos da Linguagem na PUC-SP (Muniz-Oliveira 2011).
} 


\section{ABSTRACT}

This research aims to present the results of an analysis of a text produced by a higher education teacher where we identify representations built on her/his actually work from the enunciative and semantic levels (Machado \& Bronckart 2009). We adopt the socio-discursive interactionism, which attributes to acting and language a fundamental role in human development, and the Labor Psychology (Clot 2006, 2010) which study working situations. To generate the text under analysis we employed a procedure called instruction to the double with an experienced professor of the language studies field who teaches at a public university. As a result, we identify the difficulties to the performance of some work activities, but also overcoming, showing the real work activity of the teacher.

Key-words: higher education; real work; teacher work; sociodiscursive interactionism; Labor Psychology.

\section{Introdução}

Este artigo, procedente de uma tese de doutorado (Muniz-Oliveira $2011)^{1}$, apresenta os resultados de uma investigação em que discutimos como o trabalho docente é representado em um texto produzido por um professor de ensino superior de uma universidade pública. Pesquisas revelam a problemática da profissão do professor de ensino superior que atua na pós-graduação, sugerindo que ele está atingido pelo "mal estar docente" (Gil Villa 1998), gerado pela pressão em desenvolver várias atividades prescritas pela universidade e pelas agências de fomento, sendo a produtividade e a eficiência medida em índices (Alvarez 2000; Rocha \& Rocha 2004).

Isso nos leva à hipótese de que esse "mal estar" deve se manifestar, de alguma forma, em textos que o professor comenta/descreve seu próprio trabalho. Para investigar essa hipótese, para a pesquisa de doutorado, já mencionada, realizamos entrevistas ${ }^{2}$ com professores de

1. Tese publicada em agosto de 2015 pela Editora Mercados de Letras sob o título "O trabalho docente no ensino superior: múltiplos saberes, múltiplos fazeres do professor de pós-graduação" (Muniz-Oliveira 2015) por indicação, em 2012, de Anna Rachel Machado, orientadora da tese e homenageada nesta edição especial da Revista, a quem agradeço imensamente. 
universidades públicas nas quais eles dão instruções sobre o modo de realizar as suas atividades de trabalho, evidenciando dados bastante pertinentes. Para este artigo, selecionamos alguns segmentos de uma entrevista realizada com um dos professores para a discussão das análises e apresentação dos resultados.

Partimos do princípio de que é necessário ouvir a voz do próprio trabalhador, nesse caso específico, a de um docente de ensino superior, para tentarmos compreender como se configura o seu trabalho a partir de textos produzidos por ele mesmo. As análises de diferentes textos sobre o trabalho docente podem fornecer uma nova compreensão em relação a aspectos de representações que socialmente se constroem sobre esse trabalho, possibilitando desvendar dificuldades em relação a ele.

Tendo como base os três níveis de análise: organizacional, enunciativo e semântico, expostos e discutidos por Machado \& Bronckart (2009), o objetivo deste artigo é apresentar alguns resultados das análises desses segmentos da entrevista referentes aos níveis enunciativo e semântico, conforme detalhamos na seção de procedimentos metodológicos, tendo como finalidade maior a discussão de algumas interpretações/representações sobre o agir do professor de ensino superior.

Assim, na Seção 1 trataremos de pressupostos teóricos gerais que embasam a pesquisa; na Subseção 1.1. faremos uma descrição dos procedimentos metodológicos, incluindo elementos para uma compreensão do instrumento de geração de dados; abordaremos, ainda, como ocorreu a seleção dos participantes, além de aspectos do contexto de pesquisa. Além disso, faremos uma exposição dos elementos linguístico-discursivos utilizados na análise de dados. $\mathrm{Na}$ Seção 2, apresentaremos os resultados e discussão das análises e, finalmente, na Seção 3 teceremos nossas considerações finais a respeito desses resultados.

\section{Pressupostos teóricos}

Esta pesquisa parte, de modo geral, de pressupostos teóricometodológicos oriundos de uma vertente do interacionismo social, o interacionismo sociodiscursivo (ISD) (Bronckart 1999, 2006, 2008; Machado 2008; Machado \& Bronckart 2005, 2009), que tem como 
objetivo maior investigar a problemática do agir humano, tendo se voltado, mais recentemente, a estudar o agir no trabalho. Diferente de outras vertentes, o ISD dá ênfase especial à linguagem e considera que as representações construídas nos e pelos textos têm um papel muito importante no desenvolvimento humano. Segundo Bronckart \& Machado (2004), a análise de textos sobre a relação entre linguagem e trabalho possibilita a compreensão do trabalho do professor em relação a aspectos das interpretações/representações/avaliações que socialmente se constroem sobre o agir concreto. Podemos considerar representações sociais o conjunto de crenças, conhecimentos e opiniões que são produzidos e partilhados pelos indivíduos de um mesmo grupo a respeito de determinado objeto social (Charaudeau \& Maingueneau 2008). As representações sociais, que se materializam nas produções textuais, são apropriadas pelos indivíduos, constituindo-se em representações individuais, tornando-se uma espécie de guias para ações futuras. As representações sobre a realidade só podem ser acessadas nos e pelos textos, não sendo cópias nem reflexos da realidade, pois a linguagem não espelha; ela materializa representações, que são sociais. Assim, as representações são versões da realidade, sócio-historicamente construídas. Desse modo, podemos entender melhor o trabalho a partir das representações que se constroem nos e pelos textos sobre determinada atividade, no nosso caso, o trabalho educacional.

Além da abordagem do ISD mencionada, aliamos pressupostos da Psicologia do Trabalho, especificamente a Clínica da Atividade (Clot 2001a, 2001b, 2006, 2010), que desenvolve pesquisas sobre diferentes situações de trabalho, contribuindo com vários conceitos, entre eles, o de real da atividade. Para o autor,

A atividade não é somente aquilo que se faz. O real da atividade é também o que não se faz, aquilo que não se pode fazer, o que se tenta fazer sem conseguir - os fracassos - aquilo que se desejaria ou poderia fazer, aquilo que não se faz mais, aquilo que se pensa ou sonha poder fazer em outro momento. [...] As atividades suspensas, contrariadas ou impedidas, e mesmo as contra-atividades, devem ser admitidas na análise assim como as atividades improvisadas ou antecipadas (Clot 2001a:6) 
Para a identificação desse real da atividade, a partir de representações construídas nos e pelos textos (Bronckart \& Machado 2004), uma equipe de pesquisadores da Clínica de Atividade (Clot 2001a, 2001b, 2006, 2010) desenvolveu alguns instrumentos de geração de dados, entre eles a instrução ao sósia, que foi o utilizado em nosso trabalho e que será explicitado na seção de procedimentos metodológicos, a seguir.

\subsection{Procedimentos metodológicos}

\subsubsection{O instrumento instrução ao sósia}

Para a geração dos dados, utilizamos o instrumento mencionado anteriormente denominado instrução ao sósia, com uma professora de ensino superior da área da linguagem da Universidade Estadual de Campinas (Unicamp) no ano de 2008.

A instrução ao sósia foi inicialmente utilizada por Oddone (1981) na década de 1970, na formação de trabalhadores da Fiat, na Universidade de Turim, Itália. Esse procedimento, que passou a ser bastante empregado pelos ergonomistas, foi desenvolvido por Clot (2001b, 2006, 2010) no quadro de pesquisa da Psicologia do Trabalho na Clínica de Atividade do Conservatoire Nacional des Arts et Métier (CNAM) em Paris.

Ao utilizar esse procedimento, o pesquisador se coloca na posição de substituto do trabalhador, dando a seguinte instrução: "Suponha que eu seja teu sósia e que eu vá te substituir amanhã no teu trabalho. Quais são as instruções que você deve me passar para que ninguém perceba a substituição?”.

Para desenvolver a instrução ao sósia, é necessário levar em conta as atividades de trabalho que serão focadas para que o trabalhador, nesse caso, o professor, possa dar orientações ao pesquisador de como realizá-las. Além disso, o pesquisador deve focar os possíveis problemas ou dificuldades para a realização da tarefa, buscando orientações de como agir nessas situações. Caso o professor não dê instruções de como realizar a tarefa, o pesquisador deve interrompê-lo, pedindo 
orientações de como realizá-la, questionando-o quando não compreender como realizar determinada tarefa.

Na instrução ao sósia, o pesquisador se coloca na posição de sósiasubstituto do participante de pesquisa, pedindo que este lhe dê instruções para realizar uma atividade de trabalho, o que possibilita trazer à tona especificidades da situação de trabalho, conflitos, impedimentos e dificuldades para a realização da atividade. Desse modo, partimos da hipótese de que os conflitos vividos, os impedimentos do agir, as múltiplas tarefas atribuídas ao docente podem se manifestar em textos nos quais o professor comenta/descreve/aborda o seu próprio trabalho, pois são nos e pelos textos que podemos ter acesso às representações neles construídas, o que possibilita trazer à tona o real da atividade representado.

\subsubsection{Seleção dos participantes e contexto da pesquisa}

Para a seleção dos participantes de pesquisa, estes deveriam ser professores experientes que atuassem no ensino superior, em programas de pós-graduação (stricto sensu) da área da linguagem e fossem reconhecidos no meio acadêmico, a partir do desenvolvimento e divulgação de suas pesquisas. Assim, fizemos uma consulta nas listas de professores disponíveis nos sites de duas universidades públicas reconhecidas nacionalmente: a Universidade de São Paulo (USP) e a Universidade Estadual de Campinas (Unicamp), localizadas em São Paulo-SP e Campinas-SP, respectivamente. Alguns professores nos chamaram a atenção porque já eram renomados a partir de publicações e de citações em textos acadêmicos (p.e. em livros, artigos). Consultamos o currículo Lattes desses professores e fizemos uma seleção, considerando, entre outros aspectos, o seu tempo de serviço em programas de pós-graduação. Depois, entramos em contato, por e-mail, com quatro professores, sendo que, para este artigo, apresentamos alguns resultados das análises da instrução ao sósia realizada com uma professora da Unicamp, do Instituto de Estudos da Linguagem ${ }^{4}$. 
Essa professora tinha (no período de realização da pesquisa, no ano de 2008) aproximadamente trinta anos de experiência, tendo desempenhado o papel de membro de várias comissões institucionais, coordenadora de curso, consultora ad hoc para agências de fomento, diretora de departamento, parecerista ad hoc para revistas científicas, lecionando tanto na graduação quanto na pós-graduação, entre outras atividades. Possuía notável produção intelectual e grande participação em bancas de defesa e de qualificação de mestrado e de doutorado, além de participar ativamente em congressos nacionais e internacionais.

No convite feito a essa professora, por e-mail, damos informações gerais sobre o tipo de pesquisa que seria realizado; sobre o procedimento instrução ao sósia, informando que este era um tipo de entrevista; e sobre o grupo do qual esta pesquisadora fazia parte ${ }^{5}$. Após seu pronto aceite em colaborar com a pesquisa, vários e-mails foram trocados até a data da realização do encontro em que foi realizada a instrução ao sósia. Anterior a esse encontro, foi necessário, porém, um aprofundamento teórico e metodológico sobre esse procedimento e um planejamento para que a instrução ao sósia pudesse gerar dados relevantes e suficientes para a pesquisa.

Assim, planejamos solicitar à professora a instrução/descrição das atividades de trabalho que ela iria realizar nos quatro dias após o encontro da instrução ao sósia por considerar que, nesse intervalo de tempo, haveria um número de atividades suficientes para a pesquisa. A professora retornou o e-mail listando as atividades de trabalho que realizaria nesse período, conforme elencado a seguir.

1. Encontro com alunos de graduação da disciplina Investigação Científica.

2. Elaboração de pareceres para CNPq e Fapesp ${ }^{6}$.

3. Inscrição em um congresso (preparação do resumo e envio).

4. Leitura de textos prévios de dissertação de mestrado de duas orientandas.

5. Grupo Alter: Análise de Linguagem e Trabalho Educacional e suas Relações, vinculado, em 2008, ao LAEL, PUC-SP e coordenado pela Prof ${ }^{a} \mathrm{Dr}^{\mathrm{a}}$ Anna Rachel Machado.

6. Conselho Nacional de Desenvolvimento Científico e Tecnológico e Fundação de Amparo à Pesquisa do Estado de São Paulo, respectivamente. 
5. Leitura de textos de dois orientandos de Iniciação Científica.

6. Elaboração de programa da disciplina de graduação do semestre seguinte.

7. Preparação do encontro com os alunos da disciplina Investigação Científica ${ }^{7}$.

A partir dessas atividades listadas, elaboramos um roteiro com algumas perguntas pertinentes a fim de possibilitar o acesso a representações sobre o real da atividade da docente, com base no autor mencionado (Clot 2001a, 2001b, 2006, 2010).

No dia do encontro, apresentamos brevemente o tipo de pesquisa que desenvolvemos, momento em que esclarecemos em que consistia a instrução ao sósia: a professora-instrutora deveria supor que a pesquisadora-sósia iria substituí-la em seu trabalho nos dias seguintes à entrevista. Assim, ela deveria dar instruções detalhadas para que a pesquisadora pudesse realizar o seu trabalho.

$\mathrm{Na}$ instrução ao sósia, que foi gravada e que teve a duração de aproximadamente uma hora e meia, utilizamos algumas perguntas adaptadas do roteiro elaborado como apoio para as intervenções, além de outras elaboradas no momento do diálogo, com base em nosso conhecimento teórico-metodológico a respeito desse procedimento e com base no nosso conhecimento sobre as atividades de trabalho, geralmente, desenvolvidas pelo professor de ensino superior.

Após sua realização, em outra etapa, o texto oral, resultante da gravação da instrução ao sósia, foi transcrito por nós. Depois disso, realizamos uma análise minuciosa para a identificação e intepretação dos dados, tendo como base os procedimentos seguintes.

\subsubsection{Procedimentos de análise dos dados}

No que se refere aos procedimentos de análise dos dados, como já apontado, vamos nos centrar em elementos dos níveis enunciativo e

7. Dados que fazem parte de nosso corpus de pesquisa, extraídos de um e-mail enviado pela participante de pesquisa em 2008 como resposta a um e-mail enviado por esta pesquisadora. 
semântico, fundamentando-nos em Machado \& Bronckart (2009). Em relação ao nível enunciativo, tivemos como foco a identificação:

a) de marcas de pessoas a fim de analisar como o texto representa o enunciador em relação ao seu agir docente.

b) de vozes explícitas a partir da análise de discurso relatado (discurso direto) (Authier-Revuz 2001) para estudar o grau de distanciamento ou de aproximação com que o enunciador se relaciona com as vozes; e vozes implícitas a partir de unidades de negação de asserção (Ducrot 1987) para investigar os pontos de vistas divergentes sobre aspectos do agir docente.

c) de expressões com índice se subjetividade explícita e de adjetivos que possibilitam a interpretação das avaliações que se constroem sobre as diferentes formas de agir docente e sobre os respectivos actantes.

d) de modalizadores pragmáticos, em específico, verbos auxiliares que se intercalam entre o sujeito e o verbo, que atribuem ao actante determinadas intenções e falta de capacidades.

Já em relação ao nível semântico, identificamos:

e) organizadores textuais argumentativos para detectar as razões atribuídas a aspectos do agir docente.

Na próxima seção, faremos a exposição e discussão dos resultados das análises, tendo em vista os procedimentos teórico-metodológicos apresentados.

\section{Resultados e discussão das análises}

Nesta seção, iremos apresentar os resultados obtidos a partir da descrição e interpretação dos dados, sendo que a exposição não necessariamente seguirá a divisão conforme apresentado em 1.1.3, haja vista que os elementos a que remetem esse item estão em interação constante, sendo essa divisão possível somente do ponto de vista teórico/didático.

Primeiramente, em relação às vozes, identificamos casos em que há reconstituições de outras situações de trabalho, tendo como enun- 
ciadores a professora e colegas do métier, sendo evidenciadas vozes de colegas de trabalho, como apresentamos a seguir.

$564 \mathrm{C}^{8}$.: eu tenho colegas que não leem Fapesp nada mas também não pedem nada... "se eu quiser ir para um congresso eu vou com meu dinheiro eu não peço dinheiro para ninguém... eu nunca peço dinheiro para mim para os meus alunos para nada também não recebo nada de ninguém para ler para avaliar..." é uma opção... às vezes eu acho que eles estão certos quem faz isso são coerentes né?

588C.: daí eu tenho que ir lá e fazer as coisas da Fapesp... então eu não tenho coragem de virar; tem colegas que falam isso eles falam para o aluno: "olha aluno meu eu não vou pedir bolsa para lugar nenhum "...

Esse caso mostra a voz de colegas de trabalho responsáveis pelo enunciado, revelando um modo de agir que é diferente do da professoraenunciadora. Neste caso, a professora relata que colegas de trabalho não aceitam fazer parecer para os órgãos de fomento, mas também não pedem auxílios financeiros nem para eles nem bolsas para alunos. A docente constrói representações de que não faz isso porque o aluno tem direito a bolsas, avaliando a forma de agir desses seus colegas, por um lado, como uma forma de não contribuir com os alunos, portanto, avaliando os colegas negativamente. Por outro lado, como uma forma de não aceitar trabalhos extras que acabam prejudicando as outras atividades de ensino e pesquisa, avaliando esses seus colegas como coerentes. Vemos estilos diferentes de agir e de relacionamento com as agências de fomento e com os alunos. Temos aí um conflito, pois observamos que a professora se considera "obrigada", talvez por questões de valores morais, a permitir que os alunos façam pedidos de bolsas, mesmo que isso signifique mais trabalho, prejudicando o tempo destinado a outras atividades.

8. C refere-se à professora, participante de pesquisa (oriundo do nome fictício Clara). A entrevista (instrução ao sósia) foi transcrita com base nas normas para transcrição de textos orais dos inquéritos do Projeto NURC/SP (Koch, 1997) com acréscimo dos elementos gráficos dois pontos e aspas para indicarem o uso do discurso direto, de acordo com a entoação que nos permitiu identificar uma outra voz, que não era da professora-enunciadora. O uso do itálico é para destacar o elemento analisado. 
Evidenciamos, ainda, reconstituições de situações em sala de aula, tendo como enunciadores a professora e alunos em que percebemos a voz da professora dirigida aos alunos em vários segmentos da entrevista, em que há uma reconstituição de uma situação de sala de aula (em 472C a seguir: a desinência verbal de $1^{\mathrm{a}}$ pessoa do plural: vamos), representando a professora e alunos para evidenciar os problemas/conflitos que podem ocorrer e as formas de solucioná-los. Outros casos de reconstituição de situações de sala de aula são evidenciados quando a professora usa o imperativo (em $472 \mathrm{C}$ e $246 \mathrm{C}$ a seguir: vão, vai, procura, pega) para se dirigir aos alunos, indicando um agir prescritivo em relação a eles, como podemos observamos a seguir.

472C.: [na sala de aula, quando aluno não leu o texto pedido] na hora você tem sempre algum coisa assim e isso e isso graças a Deus você vai aprendendo com o tempo né... você tem ideia com o tempo... "então vamos fazer tal coisa vão se reunir em grupo e vão fazer isso aqui assim vão discutir...”.

246C.: às vezes eu me dou ao trabalho de até ver se já tem na biblioteca da Unicamp e já aviso "olha tem na biblioteca tal vai lá e procura e pega o livro...".

Nesses exemplos, há dois planos enunciativos que aparecem a cada vez que a professora reconstitui suas atividades de trabalho, interagindo com os alunos. Nesse caso, observamos a voz da professora (uso do discurso direto) numa situação de sala de aula reconstituída na entrevista, em que o agir da professora busca não só readaptar o seu planejamento às situações de sala de aula (472C), sendo a experiência colocada como fundamental para esse aprendizado, mas também prescrever o agir dos alunos (246C). É recorrente a recriação de experiências da professora, constituindo uma experiência vivida na situação de entrevista com base em uma experiência vivida anteriormente no trabalho (Clot 2006), evidenciada a partir do recurso ao discurso direto.

Ainda sobre essa questão da inserção de vozes, observamos também dois planos enunciativos em um excerto no qual a voz da professora é colocada em cena evidenciando uma reconstituição de suas reflexões silenciosas (verbo pensar), indicando o seu planejamento em relação ao agir futuro dos alunos, prescrito pela docente. 
460C.: é eu já penso antes nisso de ir para o encontro né? eu já penso: "bom elas já leram isso para essa reunião agora eles podem ler tal coisa” às vezes eu já levo o que elas vão ler....

Esses dois planos enunciativos em que se observam reflexões da própria professora são recorrentes, evidenciando a construção de representações sobre o seu agir individual, em que ela parte de sua experiência para dar instruções à pesquisadora de como realizar o seu trabalho.

Em segundo lugar, observamos o funcionamento de modalizadores pragmáticos (querer, conseguir) e organizadores textuais argumentativos (porque) em que se atribui intenção, capacidade ou falta de e motivo ao agir individual da professora, configurando-a como responsável (ou actante ator) ${ }^{9}$ pelas suas ações de preparação para participação em bancas de defesa, como exemplificamos a seguir.

528C.: tá então eu acho melhor a gente escrever [digitar as questões/ comentários da arguição] porque [MOTIVO] depois na hora a gente não fica lá perdida os outros também falam então você fica prestando atenção nos outros e às vezes você perde o foco do que você queria dizer... [INTENÇÃO] eu não lembro dias depois o que eu li ali eu não lembro se eu não escrever eu não lembro só anotar coisas...tem gente que escreve ali do lado da tese e leva aquela tese sem digitar e na hora vai falando... eu não consigo eu não vou conseguir [FALTA DE CAPACIDADE] falar nada se fizer assim tá... porque [MOTIVO] eu não lembro eu não lembro... tem gente que é boa para isso né consegue [CAPACIDADE] lembrar na hora desenvolve lá eu não eu tenho que levar prontinho...

Nesse exemplo, a professora compara o seu modo de agir em relação à preparação para uma arguição de defesa de tese e o de colegas de trabalho: ela precisa digitar os comentários/questões sobre a tese para que consiga fazer a arguição, o que mostra um motivo pessoal/ particular na execução da atividade; já colegas de trabalho somente fazem anotações na própria tese. Em vista de sua falta de capacidade

9. O actante é considerado ator quando é colocado no texto como dotado de intenções, motivos, capacidades e, portanto, de responsabilidades sobre o seu agir (Machado et al. 2009:25). 
de agir como os colegas, a professora busca uma solução para resolver a sua dificuldade. Interessante observar que as representações construídas colocam-na como incapaz e os colegas como capazes (528C tem gente que é boa para isso, né, consegue lembrar...), o que poderia ser o inverso, ou seja, a professora construir representações de que o seu modo de agir é melhor em relação ao de seus colegas.

Temos, ainda, um outro exemplo de intenção atribuída à professora.

383C.: eu sou meio assim: "hoje eu vou fazer tal coisa" então $e u$ quero fazer aquilo tá... eu esqueço meio das outras até... no dia que vou fazer parecer esqueço de aluno esqueço de orientando vou ficar fazendo parecer...

O verbo querer revela uma intenção atribuída à professora e o advérbio meio indica que ela não esquece completamente as outras atividades, evidenciando como age em suas escolhas, trazendo à tona um conflito por ela vivido. Na verdade, ao realizar uma atividade, as outras não desaparecem; elas ficam abandonadas, atravessando a atividade que o professor está realizando (Clot 2006).

Em terceiro lugar, identificamos também as marcas de pessoas (eu, nós, a gente, você genérico) em que, em um mesmo segmento, o agir individual da professora aparece mesclado com o agir coletivo, podendo-se notar como o discurso representa o enunciador em relação ao seu agir docente.

117C.: eu fui para um congresso lá em Montevidéu em agosto da Alfal Associação de Linguística e Filologia da América Latina e nós enviamos o resumo no início do ano mas o site era horrível as explicações ali que você tinha para enviar o resumo e tudo você ficava na dúvida se o resumo tinha chegado ou não...

Neste exemplo, temos o agir individual da professora, que foi para um congresso, e o agir dos participantes do congresso, que enviam o trabalho para a apresentação. Observamos, ainda, a avaliação negativa da professora sobre um artefato simbólico do trabalho, que é o site do congresso, que causava dúvida aos participantes. 
Evidenciamos também o agir dos participantes de congresso, constituindo um agir do coletivo de trabalho (esse cuidado que você tem que ter), um agir das pessoas em geral (você não vive sem as normas) e uma avaliação negativa da professora em relação ao fato de haver prescrições diferentes para uma mesma tarefa, nesse caso, normas diferentes para cada congresso (eu acho uma chatice), como observamos a seguir.

574C.: isso é um pouco cansativo $e u$ acho... acho uma chatice... eu entendo que tem que ter as normas né? numa sociedade você não vive sem as normas... não pode cada um querer mandar o resumo que eles quiserem tá eu entendo perfeitamente não estou querendo ser anarquista mas.... cansa um pouco né? esse cuidado que você tem que ter o tempo inteiro "ai aqui o resumo tem que ter...." "aquele outro congresso já é de outra maneira" né currículo...

Nesse exemplo, identificamos uma voz a partir da negação (não estou querendo ser anarquista) em que se colocam em cena dois enunciadores em conflito: um que estava querendo ser anarquista (ou desfavorável a) em relação a tais normas mencionadas; e um outro enunciador, a professora, que rejeita esta ideia de ser anarquista, constituindo, assim, duas vozes divergentes.

Em quarto lugar, evidenciamos, ainda, uma reconstituição de uma situação de sala de aula, em que a voz da professora é trazida em cena, orientando a sósia sobre o que dizer em situações semelhantes, mostrando avaliações sobre formas de agir docente a partir de expressões ou adjetivos. A seguir, temos um exemplo.

474C.: [...] na pós na pós se os alunos chegam e falam que não deu para ler não sei o que não sei o que daí eu falo: "bom então vocês vão embora para casa e daí a gente se encontra na próxima semana é mais aquela leitura e mais essa tá" porque na pós você não vai ficar dando trabalhinho discussão em grupo é perda de tempo eu acho... "se vocês não tiveram tempo de ler vocês vão sentar aqui agora e ler então"...

Nesse exemplo, a expressão "é perda de tempo eu acho" indica uma apreciação negativa da professora sobre uma forma de proceder em sala de aula com alunos de pós-graduação em comparação com os 
de graduação (470C a 474P). Revela avaliação do agir individual da professora (eu acho) e do agir coletivo (uso do você genérico: você não vai ficar dando trabalhinhos). Quando a leitura não é feita pelos alunos, há um impedimento para que o docente siga o seu planejamento, tendo que adaptar a situação ao novo contexto, adaptação essa que terá de se levar em conta se a turma é de graduação ou de pós-graduação.

A professora também é autoavaliada (com adjetivos que a qualifica) num fragmento em que se aborda a questão dos prazos a seguir e atrasos em relação à realização das atividades. Nesse exemplo, sua experiência é colocada como fundamental para aprender a lidar com situações conflituosas.

256P.: uhn uhn bom e...ai você já falou que pode acontecer de estar muito cansada e não conseguir fazer essa leitura [de textos de alunos] e deixar para depois...

257C.: pode deixar para o outro dia... tem coisa que você às vezes atrasa viu... eu era mais neurótica com essa coisa de atrasar eu não admitia assim atrasar nada um dia... por exemplo parecer CNPq tal dia se eu atrasar um dia não posso atrasar uma semana porque... mas eu...por exemplo mas eu fiquei gripada essa semana sábado e domingo eu fiquei de cama então me atrasou muito eu antes ficava neurótica falava: "ah e agora?" mas eu num...o que eu vou fazer fiquei doente não pude fazer nada o nariz estava horrível estava com dor de cabeça você...quando essa parte aqui está ruim você não consegue raciocinar né dor de garganta...

Nesse excerto, há uma autoavaliação negativa da professora em relação ao seu comportamento ou personalidade em um tempo anterior ao da situação de enunciação, marcada pelo verbo no pretérito imperfeito (era/ficava) e pelo advérbio antes. De acordo com o dicionário Houaiss (2001), neurótico é quem sofre de neurose, que significa uma perturbação funcional de origem nervosa, gerando perturbações sensoriais, motoras e emocionais. De acordo com o dicionário de psiquiatria on line $e^{10}$, os neuróticos têm as mesmas emoções que todos nós, porém exageradamente, ou seja, eles ficam mais ansiosos, mais angustiados,

10. Disponível em $<$ http://virtualpsy.locaweb.com.br/index.php?art=333\&sec $=31>$. Acesso em: 29/jul/2010. 
mais deprimidos. Ainda nesse trecho (257C), consideramos, a partir do adjetivo neurótico no grau comparativo, que há uma comparação implícita em relação a dois tempos: um anterior ao momento de enunciação, em que a professora é configurada como mais neurótica, e outro referente ao tempo simultâneo ao da enunciação, em que a docente seria configurada como menos neurótica. Assim, revela-se a angústia e a ansiedade causadas pela preocupação com o cumprimento dos prazos preestabelecidos pelas instituições, colocando em evidência as dimensões físicas e psíquicas envolvidas no trabalho. Evidenciamos também preocupação com o prazo para a atividade de elaboração de parecer e outras atividades em "tem coisa que você atrasa" e em "parecer $C N P q$ tal dia se eu atrasar um dia não posso atrasar uma semana”.

No texto analisado, a atividade de elaboração de parecer para os órgãos de fomento é avaliada pela professora como muito trabalhosa, como podemos observar no segmento a seguir.

313C.: olha os projetos geralmente tem umas quinze páginas doze quinze páginas até vinte... o projeto que a pessoa manda ela manda um projeto de pesquisa ou ela manda um artigo que ela vai mandar/ mandou para o congresso... então é umas quinze vinte páginas que você vê... daí você vê o currículo da pessoa tá...

314P.: $\quad[$ uhn uhn

315C.: com base em tudo isso......... isso dá trabalho isso daí dá trabalho fazer parecer ((mudança de tom de voz))

316P.: [é?

O motivo pelo qual a atividade de elaboração de parecer é considerada trabalhosa é porque há configurações de que a professora mobiliza fortemente o agir cognitivo ao ter que ler e compreender o projeto do pesquisador, analisá-lo, comparando-o com o currículo da pessoa. Essa figura de agir (agir cognitivo) é necessária para que o professor possa desenvolver o agir linguageiro escrito na elaboração do parecer. Consideramos a atividade de elaboração de parecer uma atividade bastante complexa e que precisa de muita concentração para avaliar o projeto em análise, comparando-o com as informações que estão no currículo e verificando se há coerência em relação ao auxílio que está sendo solicitado (Muniz-Oliveira 2010). 
Observamos, ainda, nesse excerto 315C, o comentário descritivo entre parênteses da transcrição, fazendo referência à mudança de tom de voz da professora. Essa mudança de voz, de acordo com nossas interpretações, também revela uma avaliação da docente, enfatizando o trabalho "fatigante" de elaboração de parecer. Nesse sentido, embasamo-nos em Bakhtin (1997:132) $)^{11}$, que afirma que "quando um conteúdo objetivo é expresso [...] pela fala viva, ele é sempre acompanhado por um acento apreciativo determinado", sendo a entoação expressiva o nível mais óbvio de identificação de acento de valor ou apreciativo contido na palavra. Interpretando essa entoação expressiva em "dá trabalho fazer parecer" do excerto citado, levando em conta a situação imediata da instrução ao sósia, a voz da professora revelada na gravação expressa o sentido de dor, o que podemos considerar como uma tentativa de elucidar o quão fatigante e estressante é esta atividade.

Avançando a discussão, percebemos, também, conflitos construídos no exemplo a seguir, permeado de subjetividade da enunciadora (a partir de verbos, advérbios, adjetivos), em que a professora traz em cena as atividades representadas como agradáveis, na tabela a seguir.

Tabela 1 - As atividades agradáveis

\begin{tabular}{|c|c|}
\hline $\begin{array}{l}\text { Atividades representadas como } \\
\text { agradáveis }\end{array}$ & Exemplo \\
\hline $\begin{array}{l}\text { Estudar } \\
\text { Ler autores novos em função das } \\
\text { pesquisas } \\
\text { Preparar aulas } \\
\text { Lecionar } \\
\text { Pesquisar } \\
\text { Orientar três ou quatro alunos }\end{array}$ & $\begin{array}{l}548 \mathrm{C} . \text { olha eu acho que o trabalho da gente } \\
\text { hoje ele tem algumas coisas boas e algumas } \\
\text { coisas ruins que atrapalham a gente... } \\
\text { atrapalham a...a parte... a parte que eu gosto } \\
\text { mais do meu trabalho é a parte de estudar } \\
\text { né de ler de estudar preparar aula que é um } \\
\text { estudo que você faz né... então essa parte eu } \\
\text { gosto bastante a pesquisa ler em função da } \\
\text { pesquisa ler autores novos que eu ainda não li }\end{array}$ \\
\hline
\end{tabular}

Observamos, na Tabela 1, que as atividades representadas como agradáveis estão relacionadas ao ensino e à pesquisa. Já, na tabela a seguir, temos as atividades representadas como desagradáveis.

11. Embora essa obra tenha sua autoria atribuída a V. N. Voloshínov, fazemos referência à edição que temos em mão. 
Tabela 2 - As atividades desagradáveis

\begin{tabular}{|c|c|}
\hline $\begin{array}{l}\text { Atividades representadas como } \\
\text { desagradáveis }\end{array}$ & Exemplos \\
\hline $\begin{array}{l}\text { Elaborar muitos pareceres } \\
\text { Ler muitos trabalhos de alunos } \\
\text { Ir a reuniões } \\
\text { Participar de comissões } \\
\text { Fazer relatórios } \\
\text { Orientar mais que quatro } \\
\text { orientandos } \\
\text { Receber (e responder) e-mails em } \\
\text { excesso } \\
\text { Preencher formulários } \\
\text { Responder a pedidos burocráticos } \\
\text { Prestar contas }\end{array}$ & $\begin{array}{l}\text { 548C.: só que essas outras coisas que eu te } \\
\text { falei que às vezes...eu acho que aumentou } \\
\text { muito essa quantidade... parecer que você } \\
\text { tem que dar é...ler trabalho de aluno muito } \\
\text { você lê várias vezes de seus alunos de outros } \\
\text { alunos também relatórios que você tem que } \\
\text { fazer prestação de contas... então tem...e- } \\
\text { mail demais isso acaba tirando muito a } \\
\text { atenção da gente para aquilo que eu gostaria } \\
\text { de fazer mais né às vezes eu fico pensando } \\
\text { em me aposentar porque eu já poderia estar } \\
\text { aposentada há muitos anos e não estou porque } \\
\text { eu gosto... sinto que essa outra parte atrapalha } \\
\text { reunião por exemplo ir para reunião é uma } \\
\text { chatice né... reunião ocupa muito o tempo da } \\
\text { gente uma tarde inteira numa reunião... } \\
\text { 553P.: quantos orientandos você tem? } \\
\text { 554C.: quantos que eu tenho hoje? eu tenho } \\
\text { três de doutorado mestrado três seis e duas } \\
\text { de iniciação oito nem tenho...já tive mais... } \\
\text { mas eu já acho muito né? por exemplo ter } \\
\text { três quatro é o ideal no máximo... porque daí } \\
\text { você tem tempo realmente né... então eu acho } \\
\text { assim...e fora assim burocracia que você tem } \\
\text { que resolver comissão coisas...burocracia } \\
\text { mesmo entrega de documentos preenche } \\
\text { formulário sabe tem uma coisa assim que } \\
\text { de volta e meia estão pedindo para a gente } \\
\text { fazer... essa parte ocupa um tempo chato da } \\
\text { sua vida... }\end{array}$ \\
\hline
\end{tabular}

Já as atividades representadas como desagradáveis estão relacionadas, como observamos na Tabela 2, às atividades burocráticas e ao excesso de trabalho referente à atividade de ensino (muitos trabalhos de alunos e orientandos) e à avaliação de trabalhos acadêmicos (elaboração de pareceres). A professora constrói representações de que as atividades burocráticas acabam prejudicando outras atividades, como as voltadas ao ensino e à pesquisa. Ela compara um período em que havia menos desses trabalhos burocráticos (preencher relatórios, prestar contas etc) e que sobrava mais tempo para, de acordo com seu 
ponto de vista, as coisas fundamentais, como podemos observar no exemplo a seguir.

552C.: [reuniões] precisa ter para decidir as coisas mas eu já enjoei um pouco tá eu já enjoei na realidade... então e eu acho que...sem querer ser saudosista né assim a gente tinha menos dessa parte.... gente concentrava mais nas coisas fundamentais que é o estudo a pesquisa as aulas eram menos orientandos então a gente podia se dedicar mais... agora.

Observamos, desse modo, representações construídas de que ter tempo de dedicação para estudar, pesquisar é fundamental, o que não vem acontecendo. Consideramos que a professora faz referência a ter tempo para pesquisar tanto para poder melhor orientar as pesquisas que estão sendo desenvolvidas pelos seus orientandos de iniciação científica, mestrado e doutorado, quanto para o desenvolvimento de suas próprias pesquisas (dos professores).

Nesse sentido, consideramos que um dos aspectos que diferencia o trabalho do professor de ensino superior do de outros níveis de ensino é o tempo maior necessário para a dedicação à pesquisa, já que ele precisa de atualização constante em relação ao desenvolvimento dos trabalhos acadêmicos dos orientandos e de seus próprios. Essas representações sobre a necessidade de tempo disponível para a dedicação à pesquisa estão de acordo com determinações de documentos oficiais do Governo Federal (Muniz-Oliveira 2011).

No fragmento citado anteriormente (552C), evidenciamos dois períodos históricos:

1) antes da vigência do modelo neoliberal, em que havia tempo para as coisas fundamentais: as aulas, o estudo e a pesquisa;

2) a partir da vigência do modelo neoliberal, em que se perde muito tempo com controles burocráticos, havendo pouco tempo para as "coisas fundamentais" (Muniz-Oliveira 2011).

Evidenciamos que são diversas as atividades avaliadas pela professora. A algumas são atribuídas sentido negativo e a outras, positivo; consequentemente, há prazer na execução das atividades consideradas 
agradáveis e desprazer na realização das demais, que indica conflito para gerenciar o tempo para todas as atividades.

A relação de proximidade estabelecida entre pesquisadora que realiza a instrução ao sósia e professora faz trazer à tona não só as dificuldades da profissão, mas também diferentes modos de agir dos professores em geral, o que pode provocar o desenvolvimento profissional em relação à construção de representações sobre modelos de agir.

A partir das análises, foi possível identificar, com base nos estudos do ISD (Machado \& Bronckart 2009; Bronckart 2006, 2008), entre outros, aquilo que não é observável da atividade de trabalho da professora, aquilo que ultrapassa a tarefa prescrita ou planejada, que consideramos aqui $o$ real da atividade. (Clot 2001a, 2001b, 2006, 2010).

\section{Considerações finais}

De acordo com os resultados das análises, podemos observar os outros que a professora coloca em cena: alunos de graduação e de pós-graduação, além de colegas de trabalho, deixando a ver algumas dificuldades na realização de suas atividades de trabalho.

Em relação aos alunos, observamos que a professora interage com os da graduação e com os de pós-graduação, revelando formas específicas de agir, a depender do nível do aluno. Observamos também diferenças entre os estilos de agir da professora-participante e dos colegas de trabalho. Evidenciamos, ainda, readaptação do planejamento em sala de aula pela docente, o que mostra que a experiência é fundamental para as superações das dificuldades do trabalho e dos conflitos vividos nas situações cotidianas.

O texto analisado traz à tona também atividades consideradas agradáveis e desagradáveis. Interpretamos que as atividades desagradáveis, isto é, as burocráticas, causam desprazer, podendo levar ao sofrimento e atrapalhando o desenvolvimento das atividades voltadas ao ensino e à pesquisa, sendo essas as prazerosas. Na visão da professora, há tempo insuficiente para a dedicação a essas atividades.

Para encerrar, observamos que o estudo possibilitou trazer à tona o real da atividade construído e representado no texto analisado, os 
conflitos vividos pela professora na realização de suas atividades, o que foi possível porque a professora recria uma situação de trabalho vivida a partir do procedimento de instrução ao sósia, deixando em evidência formas de superação de algumas dificuldades vividas. Desse modo, esta pesquisa contribui, teórica e metodologicamente, para os estudos de pesquisadores que desenvolvem investigações sobre diferentes situações de trabalho que partem do ISD (Machado \& Bronckart 2009; Bronckart 2006, 2008) e/ou da Clínica da Atividade (Clot 2001a, 2001b, 2006, 2010) ou de outras abordagens teóricas, como a Ergonomia (Guérin 2001), por exemplo, que estuda a atividade de trabalho humano.

Recebido em maio de 2013

Aprovado em abril de 2015

E-mail:

sidmuniz@terra.com.br

\section{Referências Bibliográficas}

Alvarez, Denise. 2000. A temporalidade, a organização do trabalho e a avaliação da produção acadêmica: o caso do Instituto de Física da UFRJ. Tese (Doutorado em Engenharia de Produção) - Programa de Engenharia de Produção, Universidade Federal do Rio de Janeiro, Rio de Janeiro.

Authier-Revuz, Jacqueline. 2001. Palavras incertas: as não coincidências do dizer. Revisão técnica da tradução: Eni Orlandi. Campinas: Editora da Unicamp.

Bakthin, Mikhail [Voloshinov, 1929]. 1997. Marxismo e filosofia da linguagem. 8. ed. Tradução de Michel Lahud e Yara Vieira. São Paulo: Hucitec.

BRONCKART, Jean-Paul. 1999. O agir nos discursos: das concepções teóricas às concepções dos trabalhadores. Tradução de Anna Rachel Machado e Maria de Lourdes Meirelles Matêncio. Campinas: Mercado de Letras.

2006. Por que e como analisar o trabalho do professor. In: Machado, Anna Rachel; Matêncio, Maria L. Meirelles (orgs.). Atividade de Linguagem, Discurso e Desenvolvimento Humano. Campinas: Mercado de Letras. p. 203-230. 
2008. Atividade de linguagem, textos e discursos. Por um interacionismo sócio-discursivo. Tradução de Anna Rachel Machado. São Paulo: EDUC.

\& Machado, Anna Rachel. 2004. Procedimentos de análise de textos sobre o trabalho educacional. In: MAchado, Anna Rachel (org.). O ensino como trabalho: uma abordagem discursiva. Londrina: Eduel.

Charaudeau, Patrick \& Maingueneau, Dominique. 2008. Dicionário de análise do discurso. São Paulo: Contexto.

Clot, Yves. 2010. Trabalho e poder de agir. In: Lima, Francisco de Paulo Antunes; RIBEIRo, Rodrigo (org.). Tradução de Guilherme J. F. Teixeira e Marlene M. Z. Vianna. Belo Horizonte: Fabrefactum Editora. . 2006. A função psicológica do trabalho. Petrópolis, RJ: Editora Vozes. Tradução de Adail Sobral. 2001a. Clínica do trabalho, clínica do real. Le journal des psychologues, Paris, n. 185. Tradução livre de Kátia Santorum e Suyanna L. Barker. Disponível em: <http://www.pqv.unifesp.br/ clotClindotrab-tradkslb.pdf $>$. Acesso em: 8 jan. 2011.

. 2001b. Méthodologie em clinique de l'activité: l'exemple du sosie. In: Delefosse, Marie Santiago; Rouan, Georges (Dir.). Les methods qualitatives en psychologie. Paris: Dunod. p. 125-146.

Ducrot, Oswald. 1987. O dizer e o dito. Revisão técnica da tradução: Eduardo Guimarães. Campinas: Pontes.

Gil Villa, Fernando. 1998. Crise do professorado: uma análise crítica. Campinas: Papirus.

GuÉRIN, François et al. 2001. Compreender o trabalho para transformá-lo: a prática da ergonomia. São Paulo: Edgard Blücher.

Houalss, Antônio. 2001. Dicionário Houaiss da língua portuguesa. Rio de Janeiro: Objetiva.

Косн, Ingedore. 1997. A inter-ação pela linguagem. 3. ed. São Paulo: Contexto.

Machado, Anna Rachel. 2008. Por uma concepção ampliada do trabalho do professor. In: Guimarães, Ana Maria M.; Machado, Anna Rachel \& Coutinho, Antónia. (orgs.). O interacionismo sociodiscursivo: questões epistemológicas e metodológicas. Campinas, SP: Mercado de Letras. p. 77-97.

et al. 2009. Relações entre linguagem e trabalho educacional: novas perspectivas e métodos no quadro do interacionismo sociodiscursivo. In: Abreu-Tardelli, Lília \& Cristovão, Vera Lúcia Lopes (orgs.). Linguagem e Educação: O trabalho do professor em uma nova perspectiva. Campinas, SP: Mercado de Letras. p. 15-30. 
\& BRONCKART, Jean-Paul. 2009. (Re-)Configurações do trabalho do professor construídas nos e pelos textos: a perspectiva metodológica do Grupo ALTER-LAEL. In: Abreu-TARDELLI, Lília \& CRISTÓvÃo, Vera Lúcia Lopes (orgs.). Linguagem e Educação: O trabalho do professor em uma nova perspectiva. Campinas, SP: Mercado de Letras. p. 31-78.

. 2005. De que modo os textos oficiais prescrevem o trabalho do Professor? Análise comparativa de documentos brasileiros e genebrinos. D.E.L.T.A, $\mathrm{n}^{\circ}$ 21/2, p. 183-214.

Muniz-Oliveira, Siderlene. 2015. O trabalho docente no ensino superior: múltiplos saberes, múltiplos fazeres do professor de pós-graduação. Campinas, SP: Mercado de Letras.

. 2011. O trabalho representado do professor de pós-graduação de uma universidade pública. Tese. 220f (Doutorado em Linguística Aplicada e Estudos da Linguagem), Pontifícia Universidade Católica de São Paulo, SP.

2010. Um estudo sobre o trabalho de elaboração de parecer do professor de pós-graduação. D.E.L.T.A., v. 26, n. 2, p. 289-317.

Oddone, Izvar et al. 1981. Redécouvrir l'expérience ouvrière. Paris: Messidor.

Rocha, Marisa Lopes da \& Rocha, Décio. 2004. Produção de conhecimento, práticas mercantilistas e novos modos de subjetivação. Em: Psicologia e Sociedade, v. 16, n. 1, p. 13-36. 